\title{
Convergence or Divergence Between European Human Resource Management and American Human Resource Management
}

\author{
Gürhan Uysal \\ Ondokuz Mayıs University, Samsun, Turkey
}

\begin{abstract}
Major indicator of firm performance is business performance. Aims of firms and managers are to achieve firm performance. Human resource management (HRM) aims to achieve individual performance in order for firm performance. Because individuals (professionals) may have an impact on business performance. European HRM is adopting principles of American HRM. This is convergence. There are two factors that may affect divergence between Europe and USA. Divergence factors are social awareness and economic viewpoint difference. First of all, European firms consider social partners in HRM. Secondly, EU is regulated market economy and USA has liberal market economy. That may create divergence between Europe and USA.

Keywords: European human resource management (HRM), American human resource management (HRM), Chris Brewster, social context, performance
\end{abstract}

\section{Introduction}

This paper discusses convergence and divergence issue between European and American human resource management (HRM).

EU is coordinated market economy and EU firms consider social partners in market decisions. European HRM has restrictions in HRM due to coordinated market economy. Because firms have to consider stakeholders and social partners in HRM. American HRM has organisational autonomy due to liberal market economy. European HRM is becoming similar to American HRM. Difference is social context. European HRM adopts American HRM practices and European HRM adopts firm performance variations. Furthermore, Europe is becoming a deregulated economy and firms are becoming autunomous in human resource (HR). Therefore, European HRM may be defined as:

\section{European HRM = American HRM + Social Context}

American HRM has two priorities. Firstly, they are resource-based view and positive organizational attitude and behaviours. American HRM aims to develop positive organizational attitude and behaviours in employees and it perceives employees as resources. Secondly, American HRM aims to increase firm performance to provide more value to shareholders. Therefore, American HRM is involvement of HRM with

Gurhan Uysal, Ph.D., associate professor, School of Business, Ondokuz Mayıs University, Samsun, Turkey.

Correspondence concerning this article should be addressed to Gurhan Uysal at Ondokuz Mayis University, School of Business, 3rd floor, Kurupelit Campus, 55139 Atakum, Samsun, Turkey. 
corporate strategy. That is defined by Devanna, Fombrun, and Tichy (1981). Multinational companies (MNCs) provide convergence in HRM practices and national institutions and their law provide divergence in HRM. Rising of MNCs in global economy unifies HRM in global economies; therefore, MNCs lead to convergence in HRM. MNCs force local subsidiaries to adopt their HRM practices and national institutions force firms to comply with their law obligations.

\section{Literature Review}

\section{American HRM: Performance Focus}

First of all, American HRM is based on configurational perspective. It makes up HR system in management of HR in firms, for example, Huselid (1995) advocated high performance work systems (HPWS), HR systems, and HR architecture in HRM theory. Secondly, American HRM has shareholder perspective. Because USA is shareholder economy. Therefore, American HRM has firm performance targets to provide more value to shareholders. Thirdly, American HRM considers employees as a resource. This is aligned with resource-based theory of Barney (1991).

Firstly, stakeholders are important in European HRM. Therefore, European HRM has stakeholders perspective. Stakeholders are such as involvement of state, institutions, their regulations, trade unions, and social partners. Therefore, European firms consider stakeholders in management of HR. Secondly, European HRM heads for adopting American HRM, but it has social context and environment. Therefore, European HRM can be formulased as "European HRM = American HRM + Social Context". American HRM is based on two factors: (a) positive organizational attitude and behaviours; (b) individual performance. American firms aim to develop positive organisational attitude and behaviours in employees in management of HR and American firms aim to increase individual performance of employees in HRM practices. In addition, American firms are more autonomous than their European counterparts in HRM to protect rights of shareholders. European firms are restricted in HRM to protect stakeholders. However, European economies become market deregulations recently.

Calculative HRM draws importance to performance in HR, i.e., HRM enables firms to achieve firm performance. Collaborative HRM is based on psychological contracts between employees and firm. It aims to develop positive organisational attitude and behaviours. Collaborative model is called as Harvard model. Calculative model is called as Michigan model. Collaborative model is applied in European HRM and calculative HRM practice is applied in American HRM.

HR has been becoming strategic partner in American firms since 1990s. HR becomes strategic partner via employer of choice, HPWS, and a set of incentives.

American HRM is based on performance focusing on both individual and firm. European HRM is becoming more performance oriented. So, convergence between European and American HRM may appear with performance variables.

\section{European HRM: Sociatel Context}

First paper in HRM in Europe was published in 1987 in France. It argued that HRM may be applied in Europe. European HRM has contextual perspective, Brewster (2007) disagreed with universalistic perspective of HRM in European HRM. American HRM has configurational perspective. That may decrease convergence between American and European HRM. But European HRM goes to deregulations in HRM that may decrease impact of contextual perspective. 
Firstly, HRM is developing field in Europe and American MNCs deploy American HRM in European market. Secondly, European HRM is adopting firm performance target. Thirdly, European HRM is adopting firm performance target similar to American HRM. Major difference between American and European HRM is state deregulations, such as regulations in staffing, dismissal, and industrial relations. Fourthly, Europan HRM has contextual perspective. Role of state, institutions, trade unions, social partners, and labor legislations build social environment in European HRM.

The work cited by Uysal (2013) talked about leading researchers in Europe in European HRM. Most citations are given to Brewster (1992) in European HRM research (Uysal, 2014). Brewster (1992) claimed that there is a European HRM. Dickman and Sparrow (2008) said that there is "HRM in Europe" notion. European HRM is between American HRM and social context. HRM in Europe concept adopts American HRM practices.

Firstly, major difference between American and European HRM is the organisational autonomy. There is intense state involvement in European HRM. This involvement makes European HRM distinct from American HRM. Free economy culture in USA economy results in organisational autonomy in American HRM. American HRM is more autonomous in management of HR. While European HRM is restricted in HRM. This difference may emerge difference of economic systems in both markets. USA is liberal market economy and firms are free in management of HRM. EU economy is coordinated market economy and EU is regulated economy. Therefore, firms have restrictions in HRM thorough market regulations. Because coordinated market economy takes into consideration social awareness of market outcomes.

Secondly, state regulations in Europe reduce flexibility in management of HR in European firms. Major disadvantage of state involvement in European HRM is reduced employment flexibility.

Finally, firms are autonomous in American HRM to protect state. Americans aim to protect their state; therefore, firms are aoutonomous in HR. However, Europeans aim to protect their society and social rest. Therefore, firms have restrictions in HR. HRM is the American concept.

A German practitioners stressed that major difference between American and European HRM is the state regulations in staffing, dismissal, and industrial relations, for example, French labor law strongly affects training practices in France. However, Germany recently adopts deregulations in HRM instead of strict employment rules. That may increase flexibility in HR in European HRM similar to American HRM. Legislations, institutions, and social partners shape HRM in European HRM. Because social security is important priority in European HRM. But European HRM applies deregulations and flexibility in management of HR in employment practices.

\section{Research Methods}

Research methods are based on case study and interviews. Cases are European HRM and American HRM. Study compares European HRM with USA.

\section{Research Results}

Divergence between two markets may appear with two concepts:

(1) There is economic point of view between Europe and USA. Europe is regulated and coordinated market economy (network organizations), and USA has classical liberal viewpoints of Smith (1776). This economic view difference may affect HRM; 
(2) Social awareness and society are important in Europe; thus, European HRM observes social partners in HRM. That mat create divergence between Europe and USA.

Furthermore, European HRM is consistsly adopting principles of American HRM, such as autonomy and deregulations. That goal may result in convergence between the two markets.

\section{Analysis and Discussions}

Convergence between American and European HRM may be achieved through MNCs. Because American MNCs insist of applying headquarter's HRM practices in local subsidiaries. This spreads American HRM accross European market. Divergence may be achieved through social context. Because there is an economic system difference between the two markets. USA is shareholder economy and EU is stakeholder economy. EU aims to protect stakeholders. Therefore, they have state interventions, institiutional impact, and regulations in European HRM. American HRM has greater centralization in HRM in MNCs' subsidiaries. MNCs force subsidiaries to apply headquarter's HRM practices. American HRM resists against institutional requirements in host countries.

This paper argues convergence and divergence issue between European and American HRM. American HRM is based on configurational perspective. It makes up HR system in management of HR in firms, for example, Huselid (1995) advocated high performance work systems (HPWS), HR systems, and HR architecture in HRM theory. Secondly, American HRM has shareholder perspective. Because USA is shareholder economy. Therefore, American HRM has firm performance targets to provide more value to shareholders. Thirdly, American HRM considers employees as a resource. This is aligned with resource-based theory of Barney (1991).

Firstly, stakeholders are important in European HRM. Therefore, European HRM has stakeholders perspective. Stakeholders are such as involvement of state, institutions, their regulations, trade unions, and social partners. Therefore, European firms consider stakeholders in management of HR. Secondly, European HRM heads for adopting American HRM, but it has social context and environment. Therefore, European HRM can be formulased as "European HRM = American HRM + Social Context". HRM is a developing field in Europe. American MNCs deploy American HRM in European market. Thirdly, European HRM is adopting firm performance target similar to American HRM. Major difference between American and European HRM is state deregulations such as regulations in staffing, dismissal, and industrial relations. Fourthly, Europan HRM has contextual perspective. Role of state, institutions, trade unions, social partners, and labor legislations build social environment in European HRM. The work cited by Uysal (2013) talked about leading researchers in Europe in European HRM. Most citations are given to Brewster (1992) in European HRM research (Uysal, 2014). Brewster (1992) claimed that there is a European HRM. Dickman and Sparrow (2008) said that there is "HRM in Europe" notion. European HRM is between American HRM and social context. HRM in Europe concept adopts American HRM practices.

Major difference between American and European HRM is the organisational autonomy. There is intense state involvement in European HRM. This involvement makes European HRM distinct from American HRM. Free economy culture in USA economy results in organisational autonomy in American HRM. American HRM is more autonomous in management of HR. While European HRM is restricted in HRM. This difference may emerge difference of economic systems in both markets. USA is liberal market economy and firms are free in management of HRM. EU economy is coordinated market economy and EU is regulated economy. Therefore, 
firms have restrictions in HRM thorough market regulations. Because coordinated market economy takes into consideration social awareness of market outcomes. Firms are autonomous in American HRM to protect state. Americans aim to protect their state; therefore, firms are aoutonomous in HR. However, Europeans aim to protect their society and social rest. Therefore, firms have restrictions in HR.

\section{Conclusions}

EU is coordinated market economy and EU firms consider social partners in market decisions. European HRM has restrictions in HRM due to coordinated market economy. Because firms have to consider stakeholders and social partners in HRM, American HRM has organisational autonomy due to liberal market economy. European HRM is becoming similar to American HRM. Difference is social context. European HRM adopts American HRM practices and European HRM adopts firm performance variations. Furthermore, Europe is becoming a deregulated economy and firms are becoming autunomous in human resource (HR). Therefore, European HRM may be defined as:

\section{European HRM = American HRM + Social Context}

American HRM has two priorities. Firstly, they are resource-based view and positive organizational attitude and behaviours. American HRM aims to develop positive organizational attitude and behaviours in employees and it perceives employees as resources. Secondly, American HRM aims to increase firm performance to provide more value to shareholders. Therefore, American HRM is involvement of HRM with corporate strategy. That is defined by Devanna, Fombrun, and Tichy (1981). Multinational companies (MNCs) provide convergence in HRM practices and national institutions and their law provide divergence in HRM. Rising of MNCs in global economy unifies HRM in global economies; therefore, MNCs lead to convergence in HRM. MNCs force local subsidiaries to adopt their HRM practices and national institutions force firms to comply with their law obligations.

\section{References}

Barney, J. (1991). Firm resources and sustained competitive advantage. Journal of Management, 17(1), 99-120.

Brewster, C. (1992). European human resource management: Reflection of, or challenge to, the American concept? (SWP 38/92, working paper series, Cranfield School of Management, Cranfield Institute of Technology, Cranfield, UK).

Brewster, C. (2007). A European perspective on HRM. European Journal of International Management, 1(3), $239-259$.

Devanna, M. A, Fombrun, C., \& Tichy, N. (1981). Human resource management: A strategic perspective. Organizational Dynamics, 51-67. DOI: 10.1016/0090-2616(81)90038-3.

Dickman, M., \& Sparrow, P. (2008). International human resource management: A European perspective (2nd ed.). London: Routledge.

Huselid, M. A. (1995). Imapct of human resource management practices on turnover, productivity, and corporate financial performance. Academy of Management Journal, 38(3), 635-672.

Smith, A. (1776). Wealth of nations. Istanbul: Türkiye İş Bankası Publishing Company.

Uysal, G. (2013). Dimensions of American SHRM: Human capital, HR systems and firm performance. Journal of US-China Public Administration, 10(7), 720-726.

Uysal, G. (2014). Convergence or divergence between European HRM and American HRM. Journal of Business and Economics, 5(10), 1923-1928. 